\title{
Structural Study of the Self-assembled Fullerene Carboxylates: Monoadducts versus Bisadducts
}

\section{Shuiqin Zhou,* Jianying Ouyang, Patricia Golas, Feng Wang, Yi Pan}

Department of Chemistry of The College of Staten Island, Institute of Macromolecular Assembly, and The Graduate Center, City University of New York, 2800 Victory Boulevard, Staten Island, NY 10314

\section{Supporting Information}

Figure 1. UV-Vis spectra of MFCA and BFCA in THF at the concentration of $2.5 \times 10^{-5} \mathrm{~g} / \mathrm{mL}$.

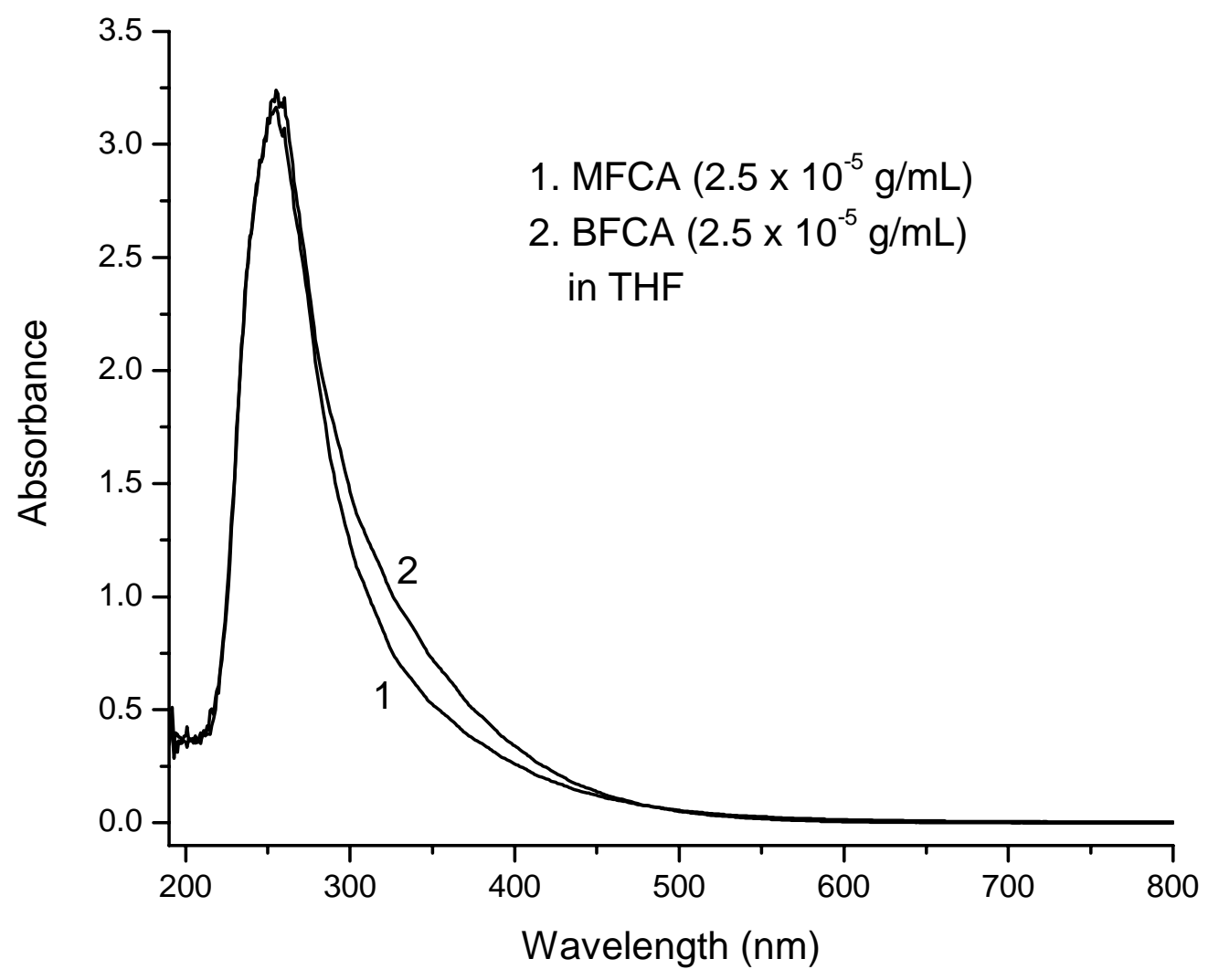


Figure 2. UV-Vis spectra of MSCF and BSCF aqueous solutions at different concentrations.

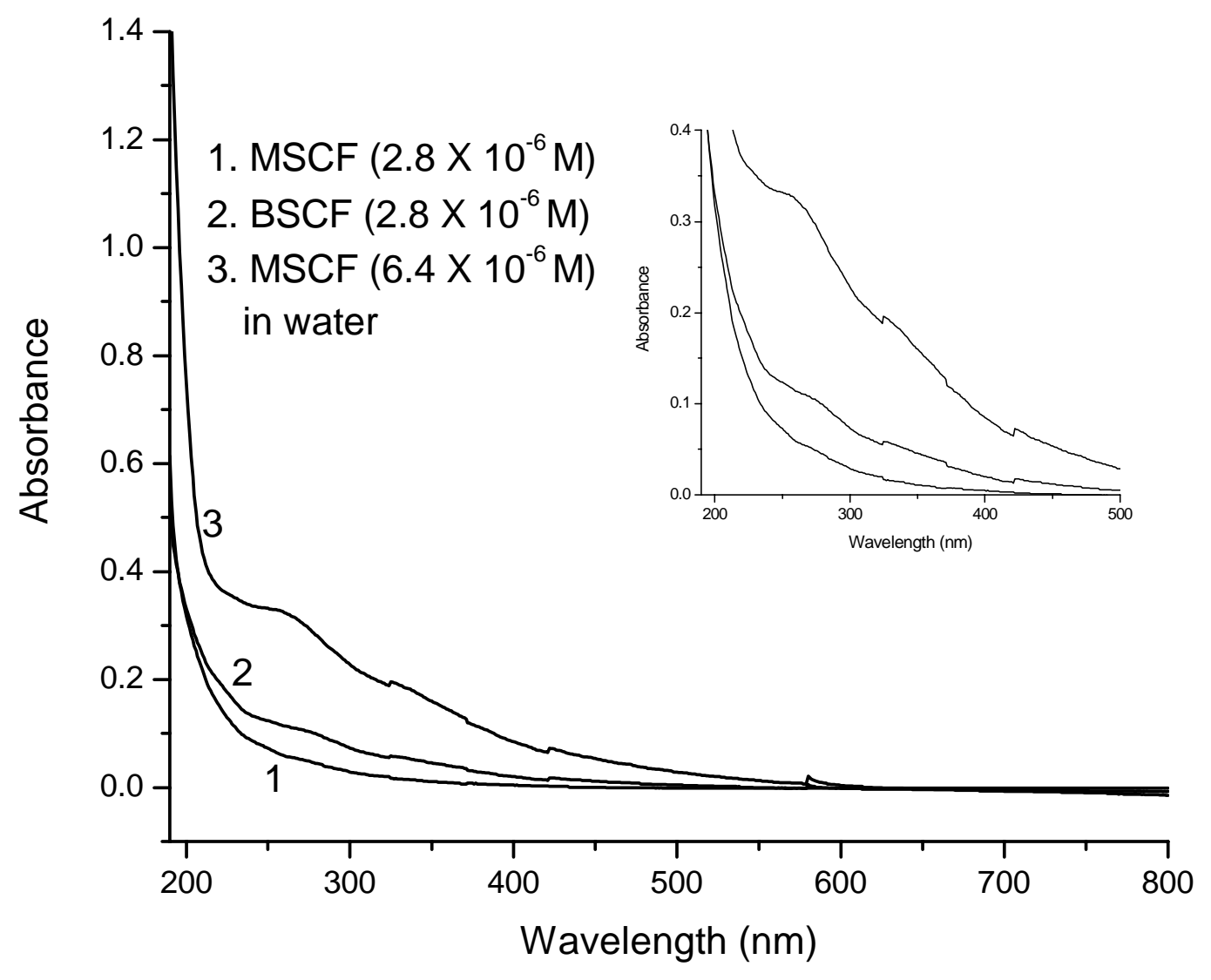


Figure 3. Concentration dependence of the apparent diffusion coefficient of the self-assembled particles from MSCF solution measured at a scattering angle of $30^{\circ}$.

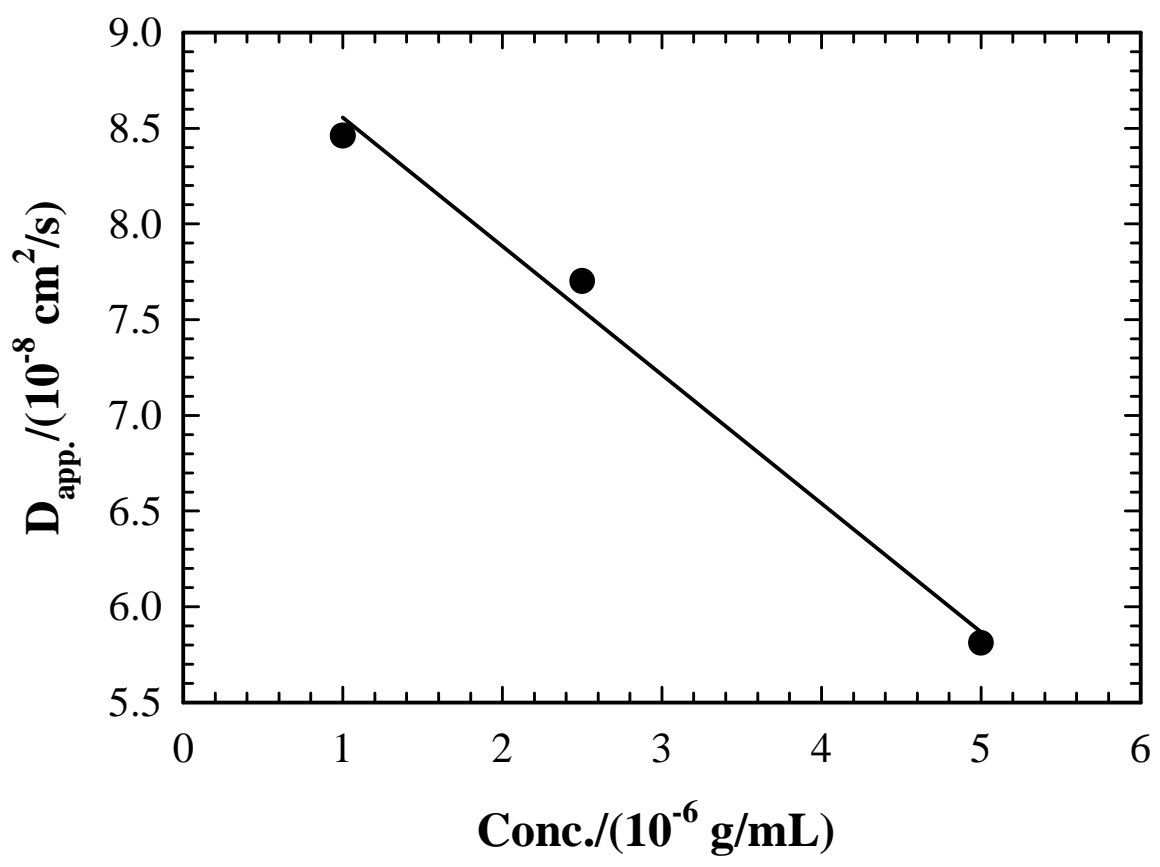

